\title{
Weak and Strong Convergence of an Implicit Iteration Process for an Asymptotically Quasi- $I$-Nonexpansive Mapping in Banach Space
}

\author{
Farrukh Mukhamedov and Mansoor Saburov \\ Department of Computational \& Theoretical Sciences, Faculty of Science, International Islamic University \\ Malaysia, P.O. Box 141, 25710 Kuantan, Malaysia \\ Correspondence should be addressed to Farrukh Mukhamedov, far75m@yandex.ru \\ Received 31 August 2009; Accepted 6 December 2009 \\ Academic Editor: Mohamed A. Khamsi \\ Copyright (c) 2010 F. Mukhamedov and M. Saburov. This is an open access article distributed \\ under the Creative Commons Attribution License, which permits unrestricted use, distribution, \\ and reproduction in any medium, provided the original work is properly cited. \\ We prove the weak and strong convergence of the implicit iterative process to a common \\ fixed point of an asymptotically quasi- $I$-nonexpansive mapping $T$ and an asymptotically quasi- \\ nonexpansive mapping $I$, defined on a nonempty closed convex subset of a Banach space.
}

\section{Introduction}

Let $K$ be a nonempty subset of a real normed linear space $X$ and let $T: K \rightarrow K$ be a mapping. Denote by $F(T)$ the set of fixed points of $T$, that is, $F(T)=\{x \in K: T x=x\}$. Throughout this paper, we always assume that $F(T) \neq \emptyset$. Now let us recall some known definitions.

Definition 1.1. A mapping $T: K \rightarrow K$ is said to be

(i) nonexpansive, if $\|T x-T y\| \leq\|x-y\|$ for all $x, y \in K$;

(ii) asymptotically nonexpansive, if there exists a sequence $\left\{\lambda_{n}\right\} \subset[1, \infty)$ with $\lim _{n \rightarrow \infty} \lambda_{n}=1$ such that $\left\|T^{n} x-T^{n} y\right\| \leq \lambda_{n}\|x-y\|$ for all $x, y \in K$ and $n \in \mathbb{N}$;

(iii) quasi-nonexpansive, if $\|T x-p\| \leq\|x-p\|$ for all $x \in K, p \in F(T)$;

(iv) asymptotically quasi-nonexpansive, if there exists a sequence $\left\{\mu_{n}\right\} \subset[1, \infty)$ with $\lim _{n \rightarrow \infty} \mu_{n}=1$ such that $\left\|T^{n} x-p\right\| \leq \mu_{n}\|x-p\|$ for all $x \in K, p \in F(T)$ and $n \in \mathbb{N}$. 
Note that from the above definitions, it follows that a nonexpansive mapping must be asymptotically nonexpansive, and an asymptotically nonexpansive mapping must be asymptotically quasi-nonexpansive, but the converse does not hold (see [1]).

If $K$ is a closed nonempty subset of a Banach space and $T: K \rightarrow K$ is nonexpansive, then it is known that $T$ may not have a fixed point (unlike the case if $T$ is a strict contraction), and even when it has, the sequence $\left\{x_{n}\right\}$ defined by $x_{n+1}=T x_{n}$ (the so-called Picard sequence) may fail to converge to such a fixed point.

In $[2,3]$ Browder studied the iterative construction for fixed points of nonexpansive mappings on closed and convex subsets of a Hilbert space. Note that for the past 30 years or so, the studies of the iterative processes for the approximation of fixed points of nonexpansive mappings and fixed points of some of their generalizations have been flourishing areas of research for many mathematicians (see for more details $[1,4]$ ).

In [5] Diaz and Metcalf studied quasi-nonexpansive mappings in Banach spaces. Ghosh and Debnath [6] established a necessary and sufficient condition for convergence of the Ishikawa iterates of a quasi-nonexpansive mapping on a closed convex subset of a Banach space. The iterative approximation problems for nonexpansive mapping, asymptotically nonexpansive mapping and asymptotically quasi-nonexpansive mapping were studied extensively by Goebel and Kirk [7], Liu [8], Wittmann [9], Reich [10], Gornicki [11], Schu [12] Shioji and Takahashi [13], and Tan and Xu [14] in the settings of Hilbert spaces and uniformly convex Banach spaces.

There are many methods for approximating fixed points of a nonexpansive mapping. $\mathrm{Xu}$ and Ori [15] introduced implicit iteration process to approximate a common fixed point of a finite family of nonexpansive mappings in a Hilbert space. Recently, Sun [16] has extended an implicit iteration process for a finite family of nonexpansive mappings, due to $\mathrm{Xu}$ and Ori, to the case of asymptotically quasi-nonexpansive mappings in a setting of Banach spaces. In [17] it has been studied the weak and strong convergence of implicit iteration process with errors to a common fixed point for a finite family of nonexpansive mappings in Banach spaces, which extends and improves the mentioned papers (see also $[18,19]$ for applications and other methods of implicit iteration processes).

There are many concepts which generalize a notion of nonexpansive mapping. One of such concepts is $I$-nonexpansivity of a mapping $T$ ([20]). Let us recall some notions.

Definition 1.2. Let $T: K \rightarrow K, I: K \rightarrow K$ be two mappings of a nonempty subset $K$ of a real normed linear space $X$. Then $T$ is said to be

(i) $I$-nonexpansive, if $\|T x-T y\| \leq\|I x-I y\|$ for all $x, y \in K$;

(ii) asymptotically $I$-nonexpansive, if there exists a sequence $\left\{\lambda_{n}\right\} \subset[1, \infty)$ with $\lim _{n \rightarrow \infty} \lambda_{n}=1$ such that $\left\|T^{n} x-T^{n} y\right\| \leq \lambda_{n}\left\|I^{n} x-I^{n} y\right\|$ for all $x, y \in K$ and $n \geq 1$;

(iii) asymptotically quasi $I$-nonexpansive mapping, if there exists a sequence $\left\{\mu_{n}\right\} \subset$ $[1, \infty)$ with $\lim _{n \rightarrow \infty} \mu_{n}=1$ such that $\left\|T^{n} x-p\right\| \leq \mu_{n}\left\|I^{n} x-p\right\|$ for all $x \in K, p \in$ $F(T) \cap F(I)$ and $n \geq 1$.

Remark 1.3. If $F(T) \cap F(I) \neq \emptyset$ then an asymptotically $I$-nonexpansive mapping is asymptotically quasi- $I$-nonexpansive. But, there exists a nonlinear continuous asymptotically quasi $I$-nonexpansive mappings which is asymptotically $I$-nonexpansive.

In [21] a weakly convergence theorem for I-asymptotically quasi-nonexpansive mapping defined in Hilbert space was proved. In [22] strong convergence of Mann iterations of $I$-nonexpansive mapping has been proved. Best approximation properties of 
I-nonexpansive mappings were investigated in [20]. In [23] the weak convergence of threestep Noor iterative scheme for an I-nonexpansive mapping in a Banach space has been established. Recently, in [24] the weak and strong convergence of implicit iteration process to a common fixed point of a finite family of $I$-asymptotically nonexpansive mappings were studied. Assume that the family consists of one $I$-asymptotically nonexpansive mapping $T$. Now let us consider an iteration method used in [24], for $T$, which is defined by

$$
\begin{gathered}
x_{1} \in K, \\
x_{n+1}=\left(1-\alpha_{n}\right) x_{n}+\alpha_{n} I^{n} y_{n}, \quad n \geq 1, \\
y_{n}=\left(1-\beta_{n}\right) x_{n}+\beta_{n} T^{n} x_{n} .
\end{gathered}
$$

where $\left\{\alpha_{n}\right\}$ and $\left\{\beta_{n}\right\}$ are two sequences in $[0,1]$. From this formula one can easily see that the employed method, indeed, is not implicit iterative processes. The used process is some kind of modified Ishikawa iteration.

Therefore, in this paper we will extend of the implicit iterative process, defined in [16], to $I$-asymptotically quasi-nonexpansive mapping defined on a uniformly convex Banach space. Namely, let $K$ be a nonempty convex subset of a real Banach space $X$ and $T: K \rightarrow K$ be an asymptotically quasi $I$-nonexpansive mapping, and let $I: K \rightarrow K$ be an asymptotically quasi-nonexpansive mapping. Then for given two sequences $\left\{\alpha_{n}\right\}$ and $\left\{\beta_{n}\right\}$ in $[0,1]$ we will consider the following iteration scheme:

$$
\begin{gathered}
x_{0} \in K, \\
x_{n}=\left(1-\alpha_{n}\right) x_{n-1}+\alpha_{n} T^{n} y_{n}, \quad n \geq 1, \\
y_{n}=\left(1-\beta_{n}\right) x_{n}+\beta_{n} I^{n} x_{n} .
\end{gathered}
$$

In this paper we will prove the weak and strong convergences of the implicit iterative process (1.2) to a common fixed point of $T$ and $I$. All results presented here generalize and extend the corresponding main results of [15-17] in a case of one mapping.

\section{Preliminaries}

Throughout this paper, we always assume that $X$ is a real Banach space. We denote by $F(T)$ and $D(T)$ the set of fixed points and the domain of a mapping $T$, respectively. Recall that a Banach space $X$ is said to satisfy Opial condition [25], if for each sequence $\left\{x_{n}\right\}$ in $X, x_{n}$ converging weakly to $x$ implies that

$$
\liminf _{n \rightarrow \infty}\left\|x_{n}-x\right\|<\liminf _{n \rightarrow \infty}\left\|x_{n}-y\right\|
$$

for all $y \in X$ with $y \neq x$. It is well known that (see [26]) inequality (2.1) is equivalent to

$$
\limsup _{n \rightarrow \infty}\left\|x_{n}-x\right\|<\limsup _{n \rightarrow \infty}\left\|x_{n}-y\right\| .
$$


Definition 2.1. Let $K$ be a closed subset of a real Banach space $X$ and let $T: K \rightarrow K$ be a mapping.

(i) A mapping $T$ is said to be semiclosed (demiclosed) at zero, if for each bounded sequence $\left\{x_{n}\right\}$ in $K$, the conditions $x_{n}$ converges weakly to $x \in K$ and $T x_{n}$ converges strongly to 0 imply $T x=0$.

(ii) A mapping $T$ is said to be semicompact, if for any bounded sequence $\left\{x_{n}\right\}$ in $K$ such that $\left\|x_{n}-T x_{n}\right\| \rightarrow 0, n \rightarrow \infty$, then there exists a subsequence $\left\{x_{n_{k}}\right\} \subset\left\{x_{n}\right\}$ such that $x_{n_{k}} \rightarrow x^{*} \in K$ strongly.

(iii) $T$ is called a uniformly $L$-Lipschitzian mapping, if there exists a constant $L>0$ such that $\left\|T^{n} x-T^{n} y\right\| \leq L\|x-y\|$ for all $x, y \in K$ and $n \geq 1$.

The following lemmas play an important role in proving our main results.

Lemma 2.2 (see [12]). Let $X$ be a uniformly convex Banach space and let $b, c$ be two constants with $0<b<c<1$. Suppose that $\left\{t_{n}\right\}$ is a sequence in $[b, c]$ and $\left\{x_{n}\right\}$ and $\left\{y_{n}\right\}$ are two sequences in $X$ such that

$$
\lim _{n \rightarrow \infty}\left\|t_{n} x_{n}+\left(1-t_{n}\right) y_{n}\right\|=d, \quad \limsup _{n \rightarrow \infty}\left\|x_{n}\right\| \leq d, \quad \limsup _{n \rightarrow \infty}\left\|y_{n}\right\| \leq d,
$$

holds some $d \leq 0$. Then $\lim _{n \rightarrow \infty}\left\|x_{n}-y_{n}\right\|=0$.

Lemma 2.3 (see [14]). Let $\left\{a_{n}\right\}$ and $\left\{b_{n}\right\}$ be two sequences of nonnegative real numbers with $\sum_{n=1}^{\infty} b_{n}<\infty$. If one of the following conditions is satisfied:

(i) $a_{n+1} \leq a_{n}+b_{n}, n \geq 1$,

(ii) $a_{n+1} \leq\left(1+b_{n}\right) a_{n}, n \geq 1$,

then the limit $\lim _{n \rightarrow \infty} a_{n}$ exists.

\section{Main Results}

In this section we will prove our main results. To formulate one, we need some auxiliary results.

Lemma 3.1. Let $X$ be a real Banach space and let $K$ be a nonempty closed convex subset of $X$. Let $T: K \rightarrow K$ be an asymptotically quasi I-nonexpansive mapping with a sequence $\left\{\lambda_{n}\right\} \subset[1, \infty)$ and $I: K \rightarrow K$ be an asymptotically quasi-nonexpansive mapping with a sequence $\left\{\mu_{n}\right\} \subset[1, \infty)$ such that $F=F(T) \cap F(I) \neq \emptyset$. Suppose $A^{*}=\sup _{n} \alpha_{n}, \Lambda=\sup _{n} \lambda_{n} \geq 1, M=\sup _{n} \mu_{n} \geq 1$ and $\left\{\alpha_{n}\right\}$ and $\left\{\beta_{n}\right\}$ are two sequences in $[0,1]$ which satisfy the following conditions:

(i) $\sum_{n=1}^{\infty}\left(\lambda_{n} \mu_{n}-1\right) \alpha_{n}<\infty$,

(ii) $A^{*}<1 / \Lambda^{2} M^{2}$.

If $\left\{x_{n}\right\}$ is the implicit iterative sequence defined by (1.2), then for each $p \in F=F(T) \cap F(I)$ the limit $\lim _{n \rightarrow \infty}\left\|x_{n}-p\right\|$ exists. 
Proof. Since $F=F(T) \cap F(I) \neq \emptyset$, for any given $p \in F$, it follows from (1.2) that

$$
\begin{aligned}
\left\|x_{n}-p\right\| & =\left\|\left(1-\alpha_{n}\right)\left(x_{n-1}-p\right)+\alpha_{n}\left(T^{n} y_{n}-p\right)\right\| \\
& \leq\left(1-\alpha_{n}\right)\left\|x_{n-1}-p\right\|+\alpha_{n}\left\|T^{n} y_{n}-p\right\| \\
& \leq\left(1-\alpha_{n}\right)\left\|x_{n-1}-p\right\|+\alpha_{n} \lambda_{n}\left\|I^{n} y_{n}-p\right\| \\
& \leq\left(1-\alpha_{n}\right)\left\|x_{n-1}-p\right\|+\alpha_{n} \lambda_{n} \mu_{n}\left\|y_{n}-p\right\| .
\end{aligned}
$$

Again from (1.2) we derive that

$$
\begin{aligned}
\left\|y_{n}-p\right\| & =\left\|\left(1-\beta_{n}\right)\left(x_{n}-p\right)+\beta_{n}\left(I^{n} x_{n}-p\right)\right\| \\
& \leq\left(1-\beta_{n}\right)\left\|x_{n}-p\right\|+\beta_{n} \mu_{n}\left\|x_{n}-p\right\| \\
& \leq\left(1-\beta_{n}\right) \mu_{n}\left\|x_{n}-p\right\|+\beta_{n} \mu_{n}\left\|I^{n} x_{n}-p\right\| \\
& \leq \mu_{n}\left\|x_{n}-p\right\|,
\end{aligned}
$$

which means

$$
\left\|y_{n}-p\right\| \leq \mu_{n}\left\|x_{n}-p\right\| \leq \lambda_{n} \mu_{n}\left\|x_{n}-p\right\|
$$

Then from (3.3) one finds

$$
\left\|x_{n}-p\right\| \leq\left(1-\alpha_{n}\right)\left\|x_{n-1}-p\right\|+\alpha_{n} \lambda_{n}^{2} \mu_{n}^{2}\left\|x_{n}-p\right\|
$$

and so

$$
\left(1-\alpha_{n} \lambda_{n}^{2} \mu_{n}^{2}\right)\left\|x_{n}-p\right\| \leq\left(1-\alpha_{n}\right)\left\|x_{n-1}-p\right\|
$$

By condition (ii) we have $\alpha_{n} \lambda_{n}^{2} \mu_{n}^{2} \leq A^{*} \Lambda^{2} M^{2}<1$, and therefore

$$
1-\alpha_{n} \lambda_{n}^{2} \mu_{n}^{2} \geq 1-A^{*} \Lambda^{2} M^{2}>0 .
$$

Hence from (3.5) we obtain

$$
\begin{aligned}
\left\|x_{n}-p\right\| & \leq \frac{1-\alpha_{n}}{1-\alpha_{n} \lambda_{n}^{2} \mu_{n}^{2}}\left\|x_{n-1}-p\right\| \\
& =\left(1+\frac{\left(\lambda_{n}^{2} \mu_{n}^{2}-1\right) \alpha_{n}}{1-\alpha_{n} \lambda_{n}^{2} \mu_{n}^{2}}\right)\left\|x_{n-1}-p\right\| \\
& \leq\left(1+\frac{\left(\lambda_{n}^{2} \mu_{n}^{2}-1\right) \alpha_{n}}{1-A^{*} \Lambda^{2} M^{2}}\right)\left\|x_{n-1}-p\right\| .
\end{aligned}
$$


By putting $b_{n}=\left(\lambda_{n}^{2} \mu_{n}^{2}-1\right) \alpha_{n} /\left(1-A^{*} \Lambda^{2} M^{2}\right)$ the last inequality can be rewritten as follows:

$$
\left\|x_{n}-p\right\| \leq\left(1+b_{n}\right)\left\|x_{n-1}-p\right\| .
$$

From condition (i) we find

$$
\begin{aligned}
\sum_{n=1}^{\infty} b_{n} & =\frac{1}{1-A^{*} \Lambda^{2} M^{2}} \sum_{n=1}^{\infty}\left(\lambda_{n}^{2} \mu_{n}^{2}-1\right) \alpha_{n} \\
& =\frac{1}{1-A^{*} \Lambda^{2} M^{2}} \sum_{n=1}^{\infty}\left(\lambda_{n} \mu_{n}-1\right)\left(\lambda_{n} \mu_{n}+1\right) \alpha_{n} \\
& \leq \frac{\Lambda M+1}{1-A^{*} \Lambda^{2} M^{2}} \sum_{n=1}^{\infty}\left(\lambda_{n} \mu_{n}-1\right) \alpha_{n}<\infty .
\end{aligned}
$$

Denoting $a_{n}=\left\|x_{n-1}-p\right\|$ in (3.8) one gets

$$
a_{n+1} \leq\left(1+b_{n}\right) a_{n}
$$

and Lemma 2.3 implies the existence of the $\operatorname{limit}_{\lim } \rightarrow \infty a_{n}$. This means the limit

$$
\lim _{n \rightarrow \infty}\left\|x_{n}-p\right\|=d
$$

exists, where $d \geq 0$ is a constant. This completes the proof.

Now we prove the following result.

Theorem 3.2. Let $X$ be a real Banach space and let $K$ be a nonempty closed convex subset of $X$. Let $T: K \rightarrow K$ be a uniformly $L_{1}$-Lipschitzian asymptotically quasi-I-nonexpansive mapping with a sequence $\left\{\lambda_{n}\right\} \subset[1, \infty)$ and let $I: K \rightarrow K$ be a uniformly $L_{2}$-Lipschitzian asymptotically quasinonexpansive mapping with a sequence $\left\{\mu_{n}\right\} \subset[1, \infty)$ such that $F=F(T) \cap F(I) \neq \emptyset$. Suppose $A^{*}=\sup _{n} \alpha_{n}, \Lambda=\sup _{n} \lambda_{n} \geq 1, M=\sup _{n} \mu_{n} \geq 1$, and $\left\{\alpha_{n}\right\}$ and $\left\{\beta_{n}\right\}$ are two sequences in $[0,1]$ which satisfy the following conditions:

(i) $\sum_{n=1}^{\infty}\left(\lambda_{n} \mu_{n}-1\right) \alpha_{n}<\infty$,

(ii) $A^{*}<1 / \Lambda^{2} M^{2}$.

Then the implicitly iterative sequence $\left\{x_{n}\right\}$ defined by (1.2) converges strongly to a common fixed point in $F=F(T) \cap F(I) \neq \emptyset$ if and only if

$$
\liminf _{n \rightarrow \infty} d\left(x_{n}, F\right)=0 .
$$

Proof. The necessity of condition (3.12) is obvious. Let us proof the sufficiency part of theorem.

Since $T, I: K \rightarrow K$ are uniformly $L$-Lipschitzian mappings, so $T$ and $I$ are continuous mappings. Therefore the sets $F(T)$ and $F(I)$ are closed. Hence $F=F(T) \cap F(I)$ is a nonempty closed set. 
Fixed Point Theory and Applications

For any given $p \in F$, we have (see (3.8))

$$
\left\|x_{n}-p\right\| \leq\left(1+b_{n}\right)\left\|x_{n-1}-p\right\|
$$

here as before $b_{n}=\left(\lambda_{n}^{2} \mu_{n}^{2}-1\right) \alpha_{n} /\left(1-A^{*} \Lambda^{2} M^{2}\right)$ with $\sum_{n=1}^{\infty} b_{n}<\infty$. Hence, one finds

$$
d\left(x_{n}, F\right) \leq\left(1+b_{n}\right) d\left(x_{n-1}, F\right) \text {. }
$$

From (3.14) due to Lemma 2.3 we obtain the existence of the $\operatorname{limit}_{n \rightarrow \infty} d\left(x_{n}, F\right)$. By condition (3.12), one gets

$$
\lim _{n \rightarrow \infty} d\left(x_{n}, F\right)=\liminf _{n \rightarrow \infty} d\left(x_{n}, F\right)=0 .
$$

Let us prove that the sequence $\left\{x_{n}\right\}$ converges to a common fixed point of $T$ and $I$. In fact, due to $1+t \leq \exp (t)$ for all $t>0$, and from (3.13), we obtain

$$
\left\|x_{n}-p\right\| \leq \exp \left(b_{n}\right)\left\|x_{n-1}-p\right\| .
$$

Hence, for any positive integers $m, n$, from (3.16) with $\sum_{n=1}^{\infty} b_{n}<\infty$ we find

$$
\begin{aligned}
\left\|x_{n+m}-p\right\| & \leq \exp \left(b_{n+m}\right)\left\|x_{n+m-1}-p\right\| \\
& \leq \exp \left(b_{n+m}+b_{n+m-1}\right)\left\|x_{n+m-2}-p\right\| \\
& \leq \cdots \\
& \leq \exp \left(\sum_{i=n+1}^{n+m} b_{i}\right)\left\|x_{n}-p\right\| \\
& \leq \exp \left(\sum_{i=1}^{\infty} b_{i}\right)\left\|x_{n}-p\right\|,
\end{aligned}
$$

which means that

$$
\left\|x_{n+m}-p\right\| \leq W\left\|x_{n}-p\right\|
$$

for all $p \in F$, where $W=\exp \left(\sum_{i=1}^{\infty} b_{i}\right)<\infty$.

Since $\lim _{n \rightarrow \infty} d\left(x_{n}, F\right)=0$, then for any given $\varepsilon>0$, there exists a positive integer number $n_{0}$ such that

$$
d\left(x_{n_{0}}, F\right)<\frac{\varepsilon}{W}
$$

Therefore there exists $p_{1} \in F$ such that

$$
\left\|x_{n_{0}}-p_{1}\right\|<\frac{\varepsilon}{W}
$$


Consequently, for all $n \geq n_{0}$ from (3.18) we derive

$$
\begin{aligned}
\left\|x_{n}-p_{1}\right\| & \leq W\left\|x_{n_{0}}-p_{1}\right\| \\
& <W \cdot \frac{\varepsilon}{W} \\
& =\varepsilon,
\end{aligned}
$$

which means that the strong convergence of the sequence $\left\{x_{n}\right\}$ is a common fixed point $p_{1}$ of $T$ and $I$. This proves the required assertion.

We need one more auxiliary result.

Proposition 3.3. Let $X$ be a real uniformly convex Banach space and let $K$ be a nonempty closed convex subset of $X$. Let $T: K \rightarrow K$ be a uniformly $L_{1}$-Lipschitzian asymptotically quasi-Inonexpansive mapping with a sequence $\left\{\lambda_{n}\right\} \subset[1, \infty)$ and let $I: K \rightarrow K$ be a uniformly $L_{2^{-}}$ Lipschitzian asymptotically quasi-nonexpansive mapping with a sequence $\left\{\mu_{n}\right\} \subset[1, \infty)$ such that $F=F(T) \cap F(I) \neq \emptyset$. Suppose $A_{*}=\inf _{n} \alpha_{n}, A^{*}=\sup _{n} \alpha_{n}, \Lambda=\sup _{n} \lambda_{n} \geq 1, M=\sup _{n} \mu_{n} \geq 1$ and $\left\{\alpha_{n}\right\}$ and $\left\{\beta_{n}\right\}$ are two sequences in $[0,1]$ which satisfy the following conditions:

(i) $\sum_{n=1}^{\infty}\left(\lambda_{n} \mu_{n}-1\right) \alpha_{n}<\infty$,

(ii) $0<A_{*} \leq A^{*}<1 / \Lambda^{2} M^{2}$,

(iii) $0<B_{*}=\inf _{n} \beta_{n} \leq \sup _{n} \beta_{n}=B^{*}<1$.

Then the implicitly iterative sequence $\left\{x_{n}\right\}$ defined by (1.2) satisfies the following:

$$
\lim _{n \rightarrow \infty}\left\|x_{n}-T x_{n}\right\|=0, \quad \lim _{n \rightarrow \infty}\left\|x_{n}-I x_{n}\right\|=0 .
$$

Proof. First, we will prove that

$$
\lim _{n \rightarrow \infty}\left\|x_{n}-T^{n} x_{n}\right\|=0, \quad \lim _{n \rightarrow \infty}\left\|x_{n}-I^{n} x_{n}\right\|=0 .
$$

According to Lemma 3.1 for any $p \in F=F(T) \cap F(I)$ we have $\lim _{n \rightarrow \infty}\left\|x_{n}-p\right\|=d$. It follows from (1.2) that

$$
\left\|x_{n}-p\right\|=\left\|\left(1-\alpha_{n}\right)\left(x_{n-1}-p\right)+\alpha_{n}\left(T^{n} y_{n}-p\right)\right\| \longrightarrow d, \quad n \longrightarrow \infty
$$

By means of asymptotically quasi- $I$-nonexpansivity of $T$ and asymptotically quasinonexpansivity of $I$ from (3.3) we get

$$
\limsup _{n \rightarrow \infty}\left\|T^{n} y_{n}-p\right\| \leq \limsup _{n \rightarrow \infty} \lambda_{n} \mu_{n}\left\|y_{n}-p\right\| \leq \limsup _{n \rightarrow \infty} \lambda_{n}^{2} \mu_{n}^{2}\left\|x_{n}-p\right\|=d .
$$

Now using

$$
\limsup _{n \rightarrow \infty}\left\|x_{n-1}-p\right\|=d
$$


Fixed Point Theory and Applications

with (3.25) and applying Lemma 2.2 to (3.24) one finds

$$
\lim _{n \rightarrow \infty}\left\|x_{n-1}-T^{n} y_{n}\right\|=0
$$

Now from (1.2) and (3.27) we infer that

$$
\lim _{n \rightarrow \infty}\left\|x_{n}-x_{n-1}\right\|=\lim _{n \rightarrow \infty}\left\|\alpha_{n}\left(T^{n} y_{n}-x_{n-1}\right)\right\|=0
$$

On the other hand, we have

$$
\begin{aligned}
\left\|x_{n-1}-p\right\| & \leq\left\|x_{n-1}-T^{n} y_{n}\right\|+\left\|T^{n} y_{n}-p\right\| \\
& \leq\left\|x_{n-1}-T^{n} y_{n}\right\|+\lambda_{n} \mu_{n}\left\|y_{n}-p\right\|,
\end{aligned}
$$

which implies

$$
\left\|x_{n-1}-p\right\|-\left\|x_{n-1}-T^{n} y_{n}\right\| \leq \lambda_{n} \mu_{n}\left\|y_{n}-p\right\| .
$$

The last inequality with (3.3) yields that

$$
\left\|x_{n-1}-p\right\|-\left\|x_{n-1}-T^{n} y_{n}\right\| \leq \lambda_{n} \mu_{n}\left\|y_{n}-p\right\| \leq \lambda_{n}^{2} \mu^{2}\left\|x_{n}-p\right\| .
$$

Then (3.27) and (3.24) with the Squeeze theorem imply that

$$
\lim _{n \rightarrow \infty}\left\|y_{n}-p\right\|=d
$$

Again from (1.2) we can see that

$$
\left\|y_{n}-p\right\|=\left\|\left(1-\beta_{n}\right)\left(x_{n}-p\right)+\beta_{n}\left(I^{n} x_{n}-p\right)\right\| \longrightarrow d, \quad n \longrightarrow \infty
$$

From (3.11) one finds

$$
\limsup _{n \rightarrow \infty}\left\|I^{n} x_{n}-p\right\| \leq \limsup _{n \rightarrow \infty} \mu_{n}\left\|x_{n}-p\right\|=d
$$

Now applying Lemma 2.2 to (3.33) we obtain

$$
\lim _{n \rightarrow \infty}\left\|x_{n}-I^{n} x_{n}\right\|=0
$$


Consider

$$
\begin{aligned}
\left\|x_{n}-T^{n} x_{n}\right\| & \leq\left\|x_{n}-x_{n-1}\right\|+\left\|x_{n-1}-T^{n} y_{n}\right\|+\left\|T^{n} y_{n}-T^{n} x_{n}\right\| \\
& \leq\left\|x_{n}-x_{n-1}\right\|+\left\|x_{n-1}-T^{n} y_{n}\right\|+L_{1}\left\|y_{n}-x_{n}\right\| \\
& =\left\|x_{n}-x_{n-1}\right\|+\left\|x_{n-1}-T^{n} y_{n}\right\|+L_{1}\left\|\beta_{n}\left(I^{n} x_{n}-x_{n}\right)\right\| \\
& =\left\|x_{n}-x_{n-1}\right\|+\left\|x_{n-1}-T^{n} y_{n}\right\|+L_{1} \beta_{n}\left\|I^{n} x_{n}-x_{n}\right\| .
\end{aligned}
$$

Then from (3.27), (3.28), and (3.35) we get

$$
\lim _{n \rightarrow \infty}\left\|x_{n}-T^{n} x_{n}\right\|=0 .
$$

Finally, from

$$
\begin{aligned}
& \left\|x_{n}-T x_{n}\right\| \leq\left\|x_{n}-T^{n} x_{n}\right\|+\left\|T^{n} x_{n}-T x_{n}\right\| \\
& \leq\left\|x_{n}-T^{n} x_{n}\right\|+L_{1}\left\|T^{n-1} x_{n}-x_{n}\right\| \\
& \leq\left\|x_{n}-T^{n} x_{n}\right\|+L_{1}\left(\left\|T^{n-1} x_{n}-T^{n-1} x_{n-1}\right\|\right. \\
& \left.\quad+\left\|T^{n-1} x_{n-1}-x_{n-1}\right\|+\left\|x_{n-1}-x_{n}\right\|\right) \\
& \leq\left\|x_{n}-T^{n} x_{n}\right\|+L_{1}\left(L_{1}\left\|x_{n}-x_{n-1}\right\|\right. \\
& \left.\quad+\left\|T^{n-1} x_{n-1}-x_{n-1}\right\|+\left\|x_{n-1}-x_{n}\right\|\right) \\
& \leq\left\|x_{n}-T^{n} x_{n}\right\|+L_{1}\left(L_{1}+1\right)\left\|x_{n}-x_{n-1}\right\|+L_{1}\left\|T^{n-1} x_{n-1}-x_{n-1}\right\|
\end{aligned}
$$

with (3.28) and (3.37) we obtain

$$
\lim _{n \rightarrow \infty}\left\|x_{n}-T x_{n}\right\|=0
$$

Analogously, one has

$$
\left\|x_{n}-I x_{n}\right\| \leq\left\|x_{n}-I^{n} x_{n}\right\|+L_{2}\left(L_{2}+1\right)\left\|x_{n}-x_{n-1}\right\|+L_{2}\left\|I^{n-1} x_{n-1}-x_{n-1}\right\|,
$$

which with (3.28) and (3.35) implies

$$
\lim _{n \rightarrow \infty}\left\|x_{n}-I x_{n}\right\|=0
$$

Now we are ready to formulate one of main results concerning weak convergence of the sequence $\left\{x_{n}\right\}$. 
Theorem 3.4. Let $X$ be a real uniformly convex Banach space satisfying Opial condition and let $K$ be a nonempty closed convex subset of $X$. Let $E: X \rightarrow X$ be an identity mapping, let $T: K \rightarrow K$ be a uniformly $L_{1}$-Lipschitzian asymptotically quasi-I-nonexpansive mapping with a sequence $\left\{\lambda_{n}\right\} \subset[1, \infty)$, and, $I: K \rightarrow K$ be a uniformly $L_{2}$-Lipschitzian asymptotically quasinonexpansive mapping with a sequence $\left\{\mu_{n}\right\} \subset[1, \infty)$ such that $F=F(T) \cap F(I) \neq \emptyset$. Suppose $A_{*}=\inf _{n} \alpha_{n}, A^{*}=\sup _{n} \alpha_{n}, \Lambda=\sup _{n} \lambda_{n} \geq 1, M=\sup _{n} \mu_{n} \geq 1$, and $\left\{\alpha_{n}\right\}$ and $\left\{\beta_{n}\right\}$ are two sequences in $[0,1]$ satisfying the following conditions:

$$
\begin{aligned}
& \text { (i) } \sum_{n=1}^{\infty}\left(\lambda_{n} \mu_{n}-1\right) \alpha_{n}<\infty, \\
& \text { (ii) } 0<A_{*} \leq A^{*}<1 / \Lambda^{2} M^{2} . \\
& \text { (iii) } 0<B_{*}=\inf _{n} \beta_{n} \leq \sup _{n} \beta_{n}=B^{*}<1 .
\end{aligned}
$$

If the mappings $E-T$ and $E-I$ are semiclosed at zero, then the implicitly iterative sequence $\left\{x_{n}\right\}$ defined by (1.2) converges weakly to a common fixed point of $T$ and $I$.

Proof. Let $p \in F$, then according to Lemma 3.1 the sequence $\left\{\left\|x_{n}-p\right\|\right\}$ converges. This provides that $\left\{x_{n}\right\}$ is a bounded sequence. Since $X$ is uniformly convex, then every bounded subset of $X$ is weakly compact. Since $\left\{x_{n}\right\}$ is a bounded sequence in $K$, then there exists a subsequence $\left\{x_{n_{k}}\right\} \subset\left\{x_{n}\right\}$ such that $\left\{x_{n_{k}}\right\}$ converges weakly to $q \in K$. Hence from (3.39) and (3.41) it follows that

$$
\lim _{n_{k} \rightarrow \infty}\left\|x_{n_{k}}-T x_{n_{k}}\right\|=0, \quad \lim _{n_{k} \rightarrow \infty}\left\|x_{n_{k}}-I x_{n_{k}}\right\|=0
$$

Since the mappings $E-T$ and $E-I$ are semiclosed at zero, therefore, we find $T q=q$ and $I q=q$, which means $q \in F=F(T) \cap F(I)$.

Finally, let us prove that $\left\{x_{n}\right\}$ converges weakly to $q$. In fact, suppose the contrary, that is, there exists some subsequence $\left\{x_{n_{j}}\right\} \subset\left\{x_{n}\right\}$ such that $\left\{x_{n_{j}}\right\}$ converges weakly to $q_{1} \in K$ and $q_{1} \neq q$. Then by the same method as given above, we can also prove that $q_{1} \in F=F(T) \cap F(I)$.

Taking $p=q$ and $p=q_{1}$ and using the same argument given in the proof of (3.11), we can prove that the $\operatorname{limits}_{\lim _{n \rightarrow \infty}}\left\|x_{n}-q\right\|$ and $\lim _{n \rightarrow \infty}\left\|x_{n}-q_{1}\right\|$ exist, and we have

$$
\lim _{n \rightarrow \infty}\left\|x_{n}-q\right\|=d, \quad \lim _{n \rightarrow \infty}\left\|x_{n}-q_{1}\right\|=d_{1}
$$

where $d$ and $d_{1}$ are two nonnegative numbers. By virtue of the Opial condition of $X$, one finds

$$
\begin{aligned}
d & =\limsup _{n_{k} \rightarrow \infty}\left\|x_{n_{k}}-q\right\|<\limsup _{n_{k} \rightarrow \infty}\left\|x_{n_{k}}-q_{1}\right\|=d_{1} \\
& =\limsup _{n_{j} \rightarrow \infty}\left\|x_{n_{j}}-q_{1}\right\|<\limsup _{n_{j} \rightarrow \infty}\left\|x_{n_{j}}-q\right\|=d .
\end{aligned}
$$

This is a contradiction. Hence $q_{1}=q$. This implies that $\left\{x_{n}\right\}$ converges weakly to $q$. This completes the proof of Theorem 3.4.

Now we formulate next result concerning strong convergence of the sequence $\left\{x_{n}\right\}$. 
Theorem 3.5. Let $X$ be a real uniformly convex Banach space and let $K$ be a nonempty closed convex subset of $X$. Let $T: K \rightarrow K$ be a uniformly $L_{1}$-Lipschitzian asymptotically quasi-Inonexpansive mapping with a sequence $\left\{\lambda_{n}\right\} \subset[1, \infty)$ and $I: K \rightarrow K$ be a uniformly $L_{2}-$ Lipschitzian asymptotically quasi-nonexpansive mapping with a sequence $\left\{\mu_{n}\right\} \subset[1, \infty)$ such that $F=F(T) \cap F(I) \neq \emptyset$. Suppose $A_{*}=\inf _{n} \alpha_{n}, A^{*}=\sup _{n} \alpha_{n}, \Lambda=\sup _{n} \lambda_{n} \geq 1, M=\sup _{n} \mu_{n} \geq 1$ and $\left\{\alpha_{n}\right\}$ and $\left\{\beta_{n}\right\}$ are two sequences in $[0,1]$ satisfying the following conditions:

(i) $\sum_{n=1}^{\infty}\left(\lambda_{n} \mu_{n}-1\right) \alpha_{n}<\infty$,

(ii) $0<A_{*} \leq A^{*}<1 / \Lambda^{2} M^{2}$.

(iii) $0<B_{*}=\inf _{n} \beta_{n} \leq \sup _{n} \beta_{n}=B^{*}<1$

If at least one mapping of the mappings $T$ and $I$ is semicompact, then the implicitly iterative sequence $\left\{x_{n}\right\}$ defined by (1.2) converges strongly to a common fixed point of $T$ and $I$.

Proof. Without any loss of generality, we may assume that $T$ is semicompact. This with (3.39) means that there exists a subsequence $\left\{x_{n_{k}}\right\} \subset\left\{x_{n}\right\}$ such that $x_{n_{k}} \rightarrow x^{*}$ strongly and $x^{*} \in K$. Since $T, I$ are continuous, then from (3.39) and (3.41) we find

$$
\left\|x^{*}-T x^{*}\right\|=\lim _{n_{k} \rightarrow \infty}\left\|x_{n_{k}}-T x_{n_{k}}\right\|=0, \quad\left\|x^{*}-I x^{*}\right\|=\lim _{n_{k} \rightarrow \infty}\left\|x_{n_{k}}-I x_{n_{k}}\right\|=0 .
$$

This shows that $x^{*} \in F=F(T) \cap F(I)$. According to Lemma 3.1 the limit $\lim _{n \rightarrow \infty}\left\|x_{n}-x^{*}\right\|$ exists. Then

$$
\lim _{n \rightarrow \infty}\left\|x_{n}-x^{*}\right\|=\lim _{n_{k} \rightarrow \infty}\left\|x_{n_{k}}-x^{*}\right\|=0,
$$

which means that $\left\{x_{n}\right\}$ converges to $x^{*} \in F$. This completes the proof.

Note that all results presented here generalize and extend the corresponding main results of [15-17] in a case of one mapping.

\section{Acknowledgment}

The authors acknowledge the MOSTI Grant 01-01-08-SF0079.

\section{References}

[1] K. Goebel and W. A. Kirk, Topics in Metric Fixed Point Theory, vol. 28 of Cambridge Studies in Advanced Mathematics, Cambridge University Press, Cambridge, UK, 1990.

[2] F. E. Browder, "Nonexpansive nonlinear operators in a Banach space," Proceedings of the National Academy of Sciences of the United States of America, vol. 54, pp. 1041-1044, 1965.

[3] F. E. Browder, "Convergence of approximants to fixed points of nonexpansive non-linear mappings in Banach spaces," Archive for Rational Mechanics and Analysis, vol. 24, pp. 82-90, 1967.

[4] Ch. Chidume, Geometric Properties of Banach Spaces and Nonlinear Iterations, vol. 1965 of Lecture Notes in Mathematics, Springer, London, UK, 2009.

[5] J. B. Diaz and F. T. Metcalf, "On the structure of the set of subsequential limit points of successive approximations," Bulletin of the American Mathematical Society, vol. 73, pp. 516-519, 1967.

[6] M. K. Ghosh and L. Debnath, "Convergence of Ishikawa iterates of quasi-nonexpansive mappings," Journal of Mathematical Analysis and Applications, vol. 207, no. 1, pp. 96-103, 1997. 
[7] K. Goebel and W. A. Kirk, "A fixed point theorem for asymptotically nonexpansive mappings," Proceedings of the American Mathematical Society, vol. 35, pp. 171-174, 1972.

[8] Q. Liu, "Iterative sequences for asymptotically quasi-nonexpansive mappings," Journal of Mathematical Analysis and Applications, vol. 259, no. 1, pp. 1-7, 2001.

[9] R. Wittmann, "Approximation of fixed points of nonexpansive mappings," Archiv der Mathematik, vol. 58, no. 5, pp. 486-491, 1992.

[10] S. Reich, "Strong convergence theorems for resolvents of accretive operators in Banach spaces," Journal of Mathematical Analysis and Applications, vol. 75, no. 1, pp. 287-292, 1980.

[11] J. Gornicki, "Weak convergence theorems for asymptotically nonexpansive mappings in uniformly convex Banach spaces," Commentationes Mathematicae Universitatis Carolinae, vol. 30, no. 2, pp. 249$252,1989$.

[12] J. Schu, "Weak and strong convergence to fixed points of asymptotically nonexpansive mappings," Bulletin of the Australian Mathematical Society, vol. 43, no. 1, pp. 153-159, 1991.

[13] N. Shioji and W. Takahashi, "Strong convergence theorems for asymptotically nonexpansive semigroups in Hilbert spaces," Nonlinear Analysis: Theory, Methods \& Applications, vol. 34, no. 1, pp. 87-99, 1998.

[14] K.-K. Tan and H.-K. Xu, "Approximating fixed points of nonexpansive mappings by the Ishikawa iteration process," Journal of Mathematical Analysis and Applications, vol. 178, no. 2, pp. 301-308, 1993.

[15] H.-K. Xu and R. G. Ori, "An implicit iteration process for nonexpansive mappings," Numerical Functional Analysis and Optimization, vol. 22, no. 5-6, pp. 767-773, 2001.

[16] Z.-H. Sun, "Strong convergence of an implicit iteration process for a finite family of asymptotically quasi-nonexpansive mappings," Journal of Mathematical Analysis and Applications, vol. 286, no. 1, pp. 351-358, 2003.

[17] F. Gu and J. Lu, "A new composite implicit iterative process for a finite family of nonexpansive mappings in Banach spaces," Fixed Point Theory and Applications, vol. 2006, Article ID 82738, 11 pages, 2006.

[18] H. Y. Li and H. Z. Li, "Strong convergence of an iterative method for equilibrium problems and variational inequality problems," Fixed Point Theory and Applications, vol. 2009, Article ID 362191, 21 pages, 2009.

[19] F. Zhang and Y. Su, "Strong convergence of modified implicit iteration processes for common fixed points of nonexpansive mappings," Fixed Point Theory and Applications, vol. 2007, Article ID 48174, 9 pages, 2007.

[20] N. Shahzad, "Generalized I-nonexpansive maps and best approximations in Banach spaces," Demonstratio Mathematica, vol. 37, no. 3, pp. 597-600, 2004.

[21] S. Temir and O. Gul, "Convergence theorem for I-asymptotically quasi-nonexpansive mapping in Hilbert space," Journal of Mathematical Analysis and Applications, vol. 329, no. 2, pp. 759-765, 2007.

[22] B. H. Rhodes and S. Temir, "Convergebce thorems for I-nonexpansive mapping," International Journal of Mathematics and Mathematical Sciences, vol. 2006, Article ID 63435, 4 pages, 2006.

[23] P. Kumam, W. Kumethong, and N. Jewwaiworn, "Weak convergence theorems of three-step Noor iterative scheme for I-quasi-nonexpansive mappings in Banach spaces," Applied Mathematical Sciences, vol. 2, no. 57-60, pp. 2915-2920, 2008.

[24] S. Temir, "On the convergence theorems of implicit iteration process for a finite family of $I$ asymptotically nonexpansive mappings," Journal of Computational and Applied Mathematics, vol. 225, no. 2, pp. 398-405, 2009.

[25] Z. Opial, "Weak convergence of the sequence of successive approximations for nonexpansive mappings," Bulletin of the American Mathematical Society, vol. 73, pp. 591-597, 1967.

[26] E. Lami Dozo, "Multivalued nonexpansive mappings and Opial's condition," Proceedings of the American Mathematical Society, vol. 38, pp. 286-292, 1973. 